\title{
Using mesoporous silica alternate nanomaterials in adsorption of phenols from
} aqueous solutions

\author{
Rasha M. Kamel ${ }^{a}$, Ahmed Shahata ${ }^{a}$, Zeinab M. Anwarb, Hamdy A. El-Kady ${ }^{\mathrm{b}}$, Esraa M. \\ Kilany $^{c^{*}}$ \\ ${ }^{a}$ Chemistry Department, Faculty of Science, Suez University, Suez, Egypt. \\ ${ }^{\mathrm{b}}$ Chemistry Department, Faculty of Science, Suez Canal University, Ismailia, Egypt. \\ ${ }^{\mathrm{c}}$ Suez University, Faculty of Petroleum and Mining Engineering, Science and Mathematics Department, Suez, Egypt
}

\begin{tabular}{|c|c|}
\hline ARTICLE INFO & ABSTRACT \\
\hline $\begin{array}{l}\text { Article history: } \\
\text { Received } 31 \text { January } 2021 \\
\text { Received in revised form } 9 \text { February } 2021 \\
\text { Accepted } 16 \text { February } 2021 \\
\text { Available online } 21 \text { February } 2021\end{array}$ & \multirow{2}{*}{$\begin{array}{l}\text { For efficient adsorbents of hazardous phenols from samples of waste, composite } \\
\text { materials utilizing mesoporous silica and organic ligands were used. The } 4 \text {-amino } \\
\text { antipyrine (4-AAP) ligand has been effectively conjugated to the mesoporous } \\
\text { nanoparticles and adsorbs phenols under appropriate conditions. The scanning } \\
\text { electron microscope (SEM), X-ray diffraction, and } \mathrm{N}_{2} \text { adsorption/desorption isotherms } \\
\text { process have been used to research this modern adsorbent content. The data } \\
\text { highlighted that the proposed sensor, as per its selectivity, response, financially } \\
\text { savvy and eco-accommodating method is highly appropriate for phenols collecting } \\
\text { from polluted water. A batch process was used: } 50 \mathrm{ml} \text { of } 50 \mathrm{mg} / \mathrm{L} \text { of each phenolic } \\
\text { solutions at pH=8.0 with (zwitterionic buffer HEPES), was introduced to } 100 \text { mg } 4- \\
\text { AAP sensor, then the mixture was submitted to filtration and the remaining phenols } \\
\text { specified by Gas Chromatography in the supernatant solution. The sorbent capacity } \\
\text { was } 151.05,82.03 \text { and } 83.47 \mathrm{mg} \text { of phenol, m-cresol, o-cresol and quinol per gram of } \\
\text { 4-AAP sensor, respectively with a correlation coefficient range of } 0.998-0.999 \text {. }\end{array}$} \\
\hline $\begin{array}{l}\text { Keywords } \\
\text { Composite, } \\
\text { adsorption, } \\
\text { phenols, } \\
\text { adsorption isotherms. }\end{array}$ & \\
\hline
\end{tabular}

\section{Introduction}

Phenol is a characteristic natural compound which is extensively used in organic preparations [1] or, for example, in separating chemistry, utilizing resins of phenol that emit phenol into the air and water [2]. Phenol is likewise a health and ecological peril [3], for instance coal tar and creosote like oil based Products contain phenol that are emitted into the atmosphere by wood burning and exhaust in cars. [4]. Decomposition of natural organic matter produces phenol, which can be processed by benzene until it reaches the human body [5]. Phenol will log into the body through the mouth, skin, eyes, eyes, and respiratory course.

As seen in animal models, Phenol can function on Various reactions, extremely nature-causing tumors and tetrogenicity [6]. Phenol can contaminate food and can cause minor, acute, sub-acute signs that end in death. Nausea, puke, diarrhea and sweating, prolonged salivation, fever, vertigo, and dark brown urine are caused.

\footnotetext{
* Corresponding authors at: Suez University

E-mail addresses: esraa.kilany@pme.suezuni.edu.eg (Esraa. M. Kilany)
}

Gastrointestinal inflammation, main nervous system, cardiovascular impacts are caused by sustained exposure to phenols [7,8]; therefore, seeking a cheap and efficient approach for purifying water is crucial and important.

In the other hand, another research analysis suggested that adsorption techniques could be an efficient way for clearance of a number of organic and inorganic contaminants by three pathways from waste water, i.e., physical adsorption, chemical adsorption and ion exchange adsorption [9]. But the water had original purity and durability since pollutants were extracted by the adsorption process using adsorbents; thus, the production of modern pollutant adsorbents has increasingly formed a study hotspot [10-12]. Due to their high adsorption potential for organic compounds, different activated carbons and silicate clays operate as the most commonly used adsorbents.

In 1943, Emerson first suggested the use of 4aminoantipyrine ligands for colorimetric phenolic substance determination. We manufactured a mesoporous, colorimetric, fluorescent sensor on silica nanoparticles as a mesoporous geometry Substrate in this article. Then, we used the sensor to detect phenols in water. The 4-AAP sensor was engineered to be water-stable, mesoporous 
silica nanoparticles by direct decoration of the 4aminoantipyrine ligand.

\section{Experimental}

\subsection{Materials and methods}

For all experiments, Milli-Q water was utilized. 4aminoantipyrine ligand (4-AAP), Cetyltrimethyl-ammonium bromide (CTAB), tetraethyl orthosilicate (TEOS), Calcium Carbonate salt $\left(\mathrm{CaCO}_{3}\right), \mathrm{HCl}$, (Phenol, o-Cresol, m-Cresol) and potassium ferricyanide (III) salt were purchased from Sigma-Aldrich. Ethyl ether, ethyl alcohol, acetone, and ammonia solution $\left(\mathrm{NH}_{3} \cdot \mathrm{H}_{2} \mathrm{O} 25\right.$ wt\%) were from Merck. Standard gas chromatography solutions with concentrations of $100 \mu \mathrm{g} / \mathrm{ml}$ of mixture were obtained from Sigma-Aldrich. Nitrogen gas carrier was from sigma chem. company. USA. To control the $\mathrm{pH}$ at 8.0 , it was used 4-(2 hydroxyethyl)-1-piperazineethanesulfonic acid (HEPES).

\section{2 preparation of Nanospheres of Mesoporous Silica (MSNs)}

The mesoporous silica nanoparticles were fabricated as reported in the ref [13-16]. Shortly MSNs synthesized by mixing a $0.5 \mathrm{~g} \mathrm{CaCO}_{3}$ dispersion solution into $100 \mathrm{ml}$ purified water, after that adding $0.5 \mathrm{~g} \mathrm{CTAB}$ and $40 \mathrm{ml}$ acetone with stirring, then adding $20 \mathrm{ml}$ diethyl ether. 2.5 $\mathrm{ml}$ of TEOS was dropped slowly after vigorous stirring, accompanied by the addition of $1.5 \mathrm{ml}$ of $\mathrm{NH}_{3}(25 \% \mathrm{wt}$ percent). The particles have been obtained by filtration. Next, $0.1 \mathrm{M} \mathrm{HCl}$ was agitated again for one hour in $200 \mathrm{ml}$. Lastly, the synthesized particles were filtered and then dried for $24 \mathrm{~h}$ at $80^{\circ} \mathrm{C}$. The finished product has been calcinated for $8 \mathrm{~h}$ at $550{ }^{\circ} \mathrm{C}$.

\subsection{4-aminoantipyrine Sensor synthesis}

The direct immobilization method was used in 4-AAP solid sensor fabricating by adding $30 \mathrm{~mL}$ of ethanol solution that includes $0.12 \mathrm{~g}$ of $4-\mathrm{AAP}$ to $1 \mathrm{~g}$ of MSN and stirred for eight hours. With bi-distilled water, the produced 4-AAP sensor was softly washed and then the dry sensor was removed to grind well.

\subsection{Instruments}

To investigate the crystal structure of the samples, patterns of a wide angle X-ray diffraction (WAXRD) have been assessed utilizing Bruker D8 Discover diffractometer at $40 \mathrm{kV}$, an $45 \mathrm{~mA}$. The isotherms for adsorption/desorption were obtained via Quantachrom Autosorb system at $77 \mathrm{~K}$. The specimens have been outgassed at $200^{\circ} \mathrm{C}$ for $2 \mathrm{~h}$. Calculations of the BET surface areas were made from $\mathrm{N}_{2}$ adsorption data. A fieldemission scanning electron microscopy (FESEM) (Hitachi S-4300) that conducted at $20 \mathrm{keV}$ was assessed.

Phenol concentrations were obtained by HewlettPackard (HP) 5890 Series II Gas Chromatography with a column of capillaries that has a Nickel 63 flame ionization detector at $270{ }^{\circ} \mathrm{C}$. The transporter gas was nitrogen, Extraction has been achieved with $\mathrm{H}_{2} \mathrm{SO}_{4}$ by changing $\mathrm{pH}$ (1-2) and extracting 3 times using $60 \mathrm{ml}$ of $\mathrm{CH}_{3} \mathrm{Cl}$. Rotatory evaporation was conducted using the APHA process for evaporation [17] pre and post sensor treatment.

\section{Results and discussion}

The morphology and structure of Nanospheres of Mesoporous Silica (MSNs):

Wide edge X-ray diffraction (WAXRD) revealed a strong peak of diffraction in the region of $2 \theta=17-30$ (Fig.1), that displayed standard ranges of electronic density [18]. The mesoporous structure was not altered by the load of the 4-AAP to the MSNs surface.

As a consequence of $\mathrm{N}_{2}$ adsorption data, MSNs and the 4-AAP sensor samples demonstrated type IV, and wide-ranging hysteresis loop at $\mathrm{p} / \mathrm{p}_{\mathrm{o}}=0.4-1.0$.

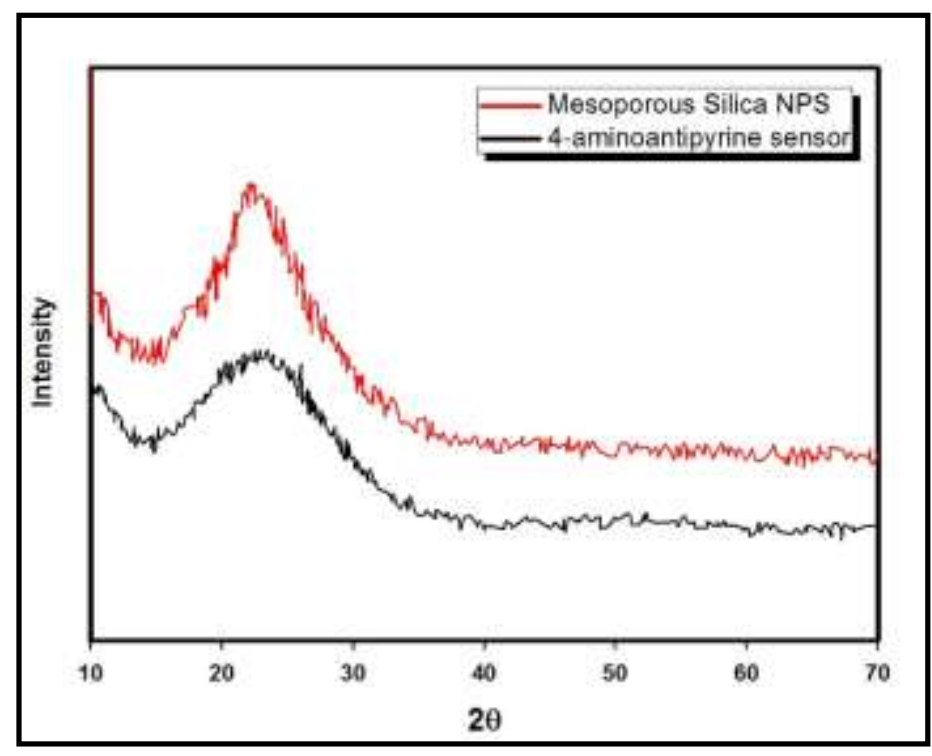

Fig. (1): wide-angle XRD (WAXRD) patterns of the calcined MSNs and 4-AAP sensor samples.

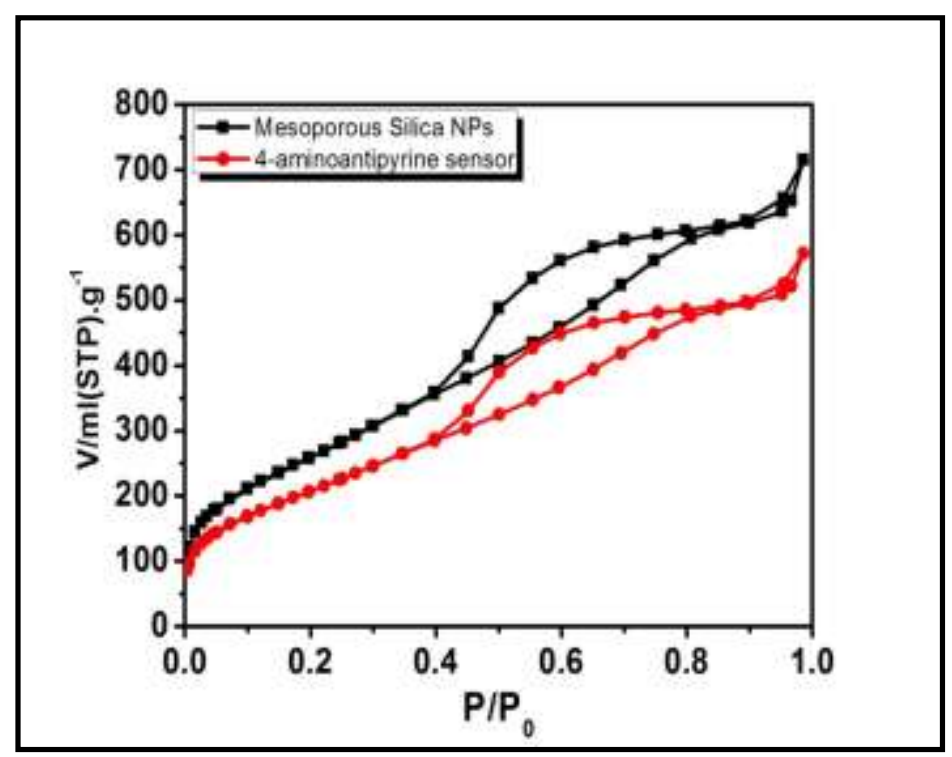

Fig. (2): Nitrogen adsorption isotherms of MSNs and the 4AAP sensor. 
Fig. 2 exhibited the calculated value of specific surface area $\left(\mathrm{S}_{\mathrm{BET}}\right)$ of the MSNs was $970.95 \mathrm{~m}^{2} / \mathrm{g}$, and upon load of ligand moieties it reduced to $776.76 \mathrm{~m}^{2} / \mathrm{g}$, this outcome shows that the 4-AAP sensor preserves the MSNs mesoporosity.

FESEM images of both the bare and modified MSNs are revealed in (Fig. $3 \mathrm{a}, \mathrm{b}$ ). It is obvious that the two

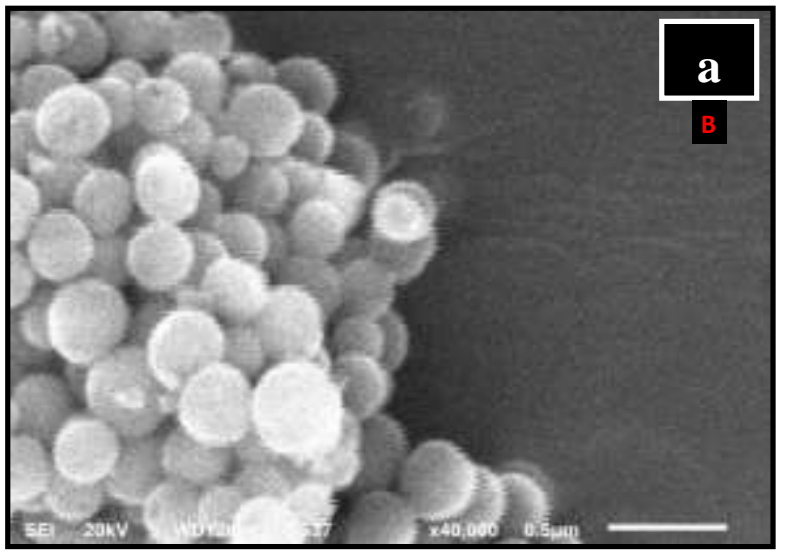

materials function as nanostructures in the 300-400 nm region. It additionally proposed that after distribution, there was no seen change in the design of our 4-AAP all along the surface, so these observations are compliant with the findings of XRD.

Fig. (3 a, b): FESEM images of the MSNs (a) and 4-AAP sensor (b).

\section{Adsorption capacity}

Sorption capacity is a fundamental element since it specifies the quantity of sorbent needed from a particular solution for the analyte quantitative enhancement. To assess the 4-AAP sensor's adsorption capacity, A batch process was used: $50 \mathrm{ml}$ of $50 \mathrm{mg} / \mathrm{L}$ of each phenolic solutions at $\mathrm{pH}=8.0$ with (zwitterionic buffer HEPES), was introduced to $100 \mathrm{mg}$ 4-AAP sensor, then the mixture was submitted to filtration and the remaining phenols specified by Gas Chromatography in the clear solution. The sorbent capacity was $151.05,82.03$ and $83.47 \mathrm{mg}$ of phenol, mcresol, and o-cresol per gram of 4-AAP sensor, respectively.

The effect of various phenolic compound concentrations on the capacity of adsorption has also been observed (Fig. 4-6). According to the following equation, the Langmuir isotherm was expressed at fixed temperature by coverage of phenol on the 4-AAP sensor [19]:

$$
C_{e} / q_{e}=C_{e} / q_{m}+1 / K_{L} q_{m}
$$

At which $C_{e}$ is the phenolic compounds concentration at equilibrium in solution $(\mathrm{mg} / \mathrm{L}), q_{e}$ is the phenolic compounds amount that have adsorbed at equilibrium on the 4-AAP sensor $(\mathrm{mg} / \mathrm{g}), q_{m}$ is the adsorbed phenolic compounds amount to produce a monolayer coverage $(\mathrm{mg} / \mathrm{g})$, and $K_{L}$ is the adsorption of Langmuir equilibrium constant.

Our studies have shown that the capacity of equilibrium adsorption rises with rising phenolic compound concentrations. From the adsorption experiment, the $\mathrm{C}_{e} / \mathrm{q}_{\mathrm{e}}$ vs $C_{e}$ plot produce a straight line and this shows the development of a monolayer coverage of phenolic compounds on the 4-AAP sensor surface (Fig. 4-6 insert).
From the intercept and slope of the linear ranges of the Langmuir plots, the constant of Langmuir coverage $\left(\mathrm{K}_{\mathrm{L}}\right)$ and functional adsorption capacity $\left(\mathrm{q}_{\mathrm{m}}\right)$ were obtained, correspondingly. The linear curves of adsorption illustrate that it is possible to extract a wide variety of phenolic compound concentrations. A straight plot has a coefficient of correlation of 0.998-0.999 reveals that the Langmuir isotherms of adsorption describe the phenolic adsorption experiments for phenolic compounds (phenol, m-cresol and o-cresol) the data are collected in Tables (1-4).

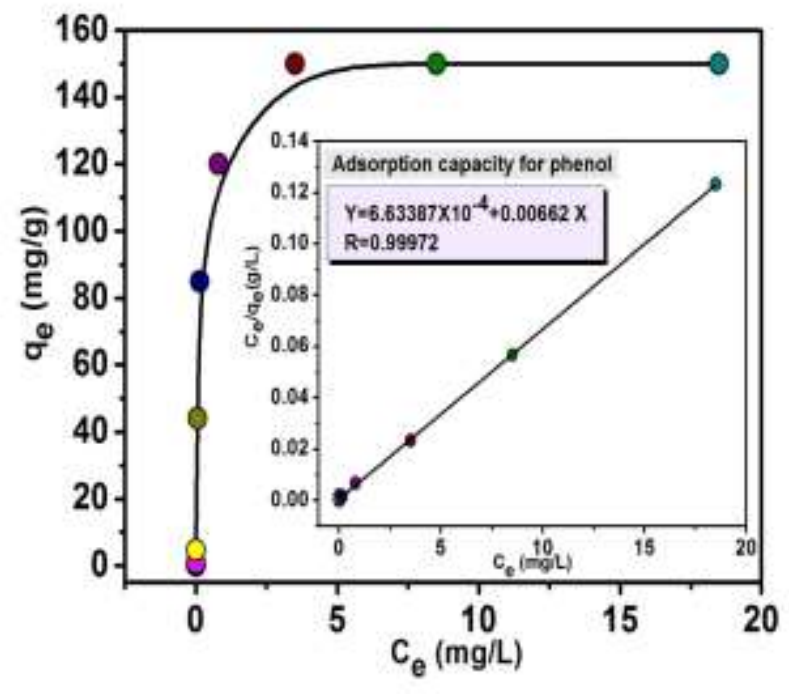

Fig. (4): The Isotherms for the adsorption of different concentrations of phenol compound. The insets show the linear form of the Langmuir plots for the adsorption of phenol compound onto the 4-AAP sensor adsorbent at room temperature. 


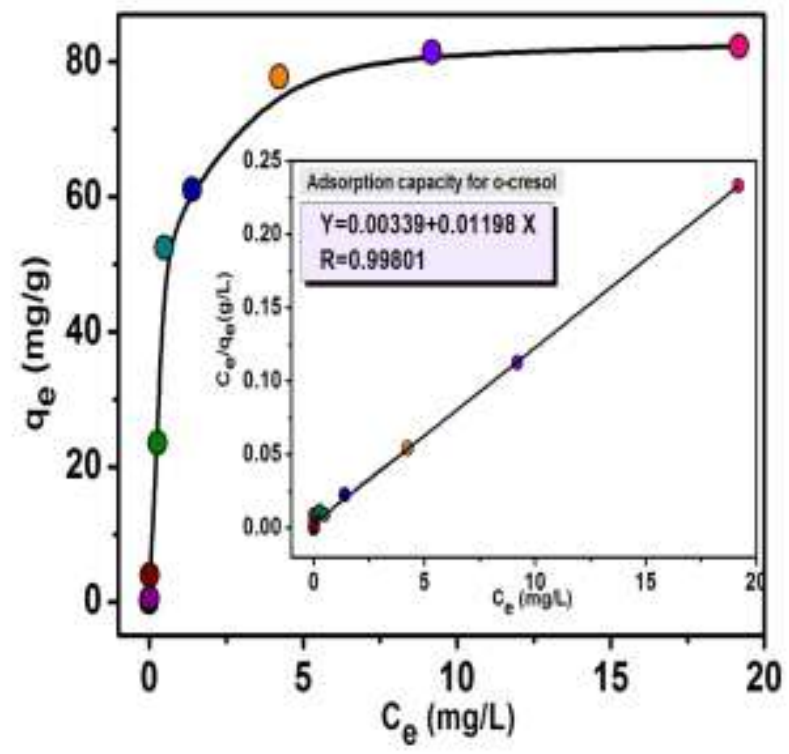

Fig. (5): The Isotherms for the adsorption of different concentrations of o-Cresol compound. The insets show the linear form of the Langmuir plots for the adsorption of oCresol compound onto the 4-AAP sensor adsorbent at room temperature.

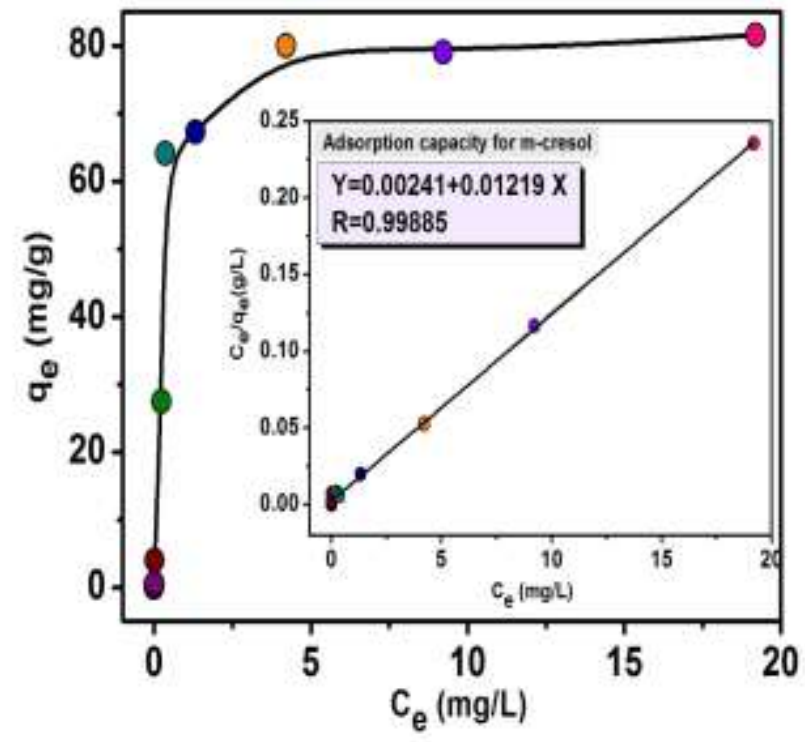

Fig. (6): The Isotherms for the adsorption of different concentrations of $\mathrm{m}$-Cresol compound. The insets show the linear form of the Langmuir plots for the adsorption of $\mathrm{m}$-Cresol compound onto the 4-AAP sensor adsorbent at room temperature.
Table (1): The parameters of Isotherm for the adsorption of different concentrations of Phenol compound.

\begin{tabular}{c|c|c|c}
\hline $\begin{array}{c}{[\text { Phenol] }} \\
(\mathbf{p p m})\end{array}$ & $\mathbf{C}_{\mathrm{e}}$ & $\mathbf{q}_{\mathrm{e}}$ & $\mathbf{C}_{\mathrm{e}} / \mathbf{q}_{\mathbf{e}}$ \\
\hline 0.0001 & 0.000000025 & 0.0099975 & $2.50063 \times 10^{-6}$ \\
0.0005 & 0.0000005 & 0.04995 & $1.001 \times 10^{-5}$ \\
0.001 & 0.00005 & 0.095 & 0.0005263 \\
0.005 & 0.000125 & 0.4875 & 0.000256 \\
0.01 & 0.0017 & 0.83 & 0.0020481 \\
0.05 & 0.003 & 4.7 & 0.0006382 \\
0.5 & 0.06 & 44 & 0.0013636 \\
1 & 0.15 & 85 & 0.0017647 \\
2 & 0.8 & 120 & 0.0066666 \\
5 & 3.5 & 150 & 0.0233333 \\
10 & 8.5 & 150 & 0.0566666 \\
20 & 18.5 & 150 & 0.1233333 \\
\hline
\end{tabular}

Table (2): The parameters of Isotherm for the adsorption of different concentrations of o-Cresol compound.

\begin{tabular}{c|c|c|c}
\hline $\begin{array}{c}\text { [o-Cresol] } \\
(\mathbf{p p m})\end{array}$ & $\mathbf{C}_{\mathrm{e}}$ & $\mathbf{q}_{\mathrm{e}}$ & $\mathbf{C}_{\mathrm{e}} / \mathbf{q}_{\mathrm{e}}$ \\
\hline 0.0001 & $1.79 \times 10^{-8}$ & 0.00999821 & $1.79032 \times 10^{-6}$ \\
0.0005 & $7.75 \times 10^{-8}$ & 0.04999225 & $1.55024 \times 10^{-6}$ \\
0.001 & 0.0000621 & 0.09379 & 0.0006621 \\
0.005 & 0.000526 & 0.4474 & 0.0011756 \\
0.01 & 0.004731 & 0.5269 & 0.0089789 \\
0.05 & 0.01032 & 3.968 & 0.0026008 \\
0.5 & 0.265 & 23.5 & 0.0112765 \\
1 & 0.4751 & 52.49 & 0.0090512 \\
2 & 1.389 & 61.1 & 0.0227332 \\
5 & 4.223 & 77.7 & 0.05435006 \\
10 & 9.186 & 81.4 & 0.1128501 \\
20 & 19.1775 & 82.25 & 0.233161 \\
\hline
\end{tabular}

Table (3): The parameters of Isotherm for the adsorption of different concentrations of $\mathrm{m}$-Cresol compound.

\begin{tabular}{c|c|c|c}
\hline $\begin{array}{c}\text { [m-Cresol] } \\
(\mathbf{p p m})\end{array}$ & $\mathbf{C}_{\mathrm{e}}$ & $\mathbf{q}_{\mathrm{e}}$ & $\mathbf{C}_{\mathrm{e}} / \mathbf{q}_{\mathbf{e}}$ \\
\hline 0.0001 & $1.53 \times 10^{-8}$ & 0.00999847 & $1.53023 \times 10^{-6}$ \\
0.0005 & 0.000000071 & 0.0499929 & $1.4202 \times 10^{-6}$ \\
0.001 & 0.000059 & 0.0941 & 0.000626993 \\
0.005 & 0.000498 & 0.4502 & 0.001106175 \\
0.01 & 0.00422 & 0.578 & 0.007301038 \\
0.05 & 0.00993 & 4.007 & 0.002478163 \\
0.5 & 0.226 & 27.4 & 0.008248175 \\
1 & 0.359 & 64.1 & 0.005600624 \\
2 & 1.328 & 67.2 & 0.019761905 \\
5 & 4.2 & 80 & 0.0525 \\
10 & 9.21 & 79 & 0.116582278 \\
20 & 19.185 & 81.5 & 0.235398773 \\
\hline
\end{tabular}


Table (4): Analytical parameters of Langmuir adsorption isotherms for phenolic compounds.

\begin{tabular}{c|c|c|c|c|c|}
$\begin{array}{c}\text { Phenolic } \\
\text { Compound }\end{array}$ & Slope & $\mathbf{R}$ & Intercept & $q_{\mathrm{m}}$ & $\mathrm{K}_{\mathrm{L}}$ \\
\hline Phenol & 0.0066 & 0.999 & 0.00066 & 151.06 & 9.979 \\
\hline O-Cresol & 0.0119 & 0.998 & 0.00339 & 83.472 & 3.533 \\
\hline m-Cresol & 0.0121 & 0.998 & 0.00241 & 82.034 & 5.058 \\
\hline
\end{tabular}

R: Correlation coefficient; $\mathbf{q}_{\mathrm{m}}$ : the amount of phenolic compounds adsorbed to form a monolayer coverage $(\mathrm{mg} / \mathrm{g}) ; \mathrm{K}_{\mathrm{L}}$ : is the Langmuir adsorption equilibrium constant.

\section{References}

[1] Burton S.G.; Current Organic Chemistry 7 (2003) 1317-1331.

[2] Zhang X.; Li A.; Jiang Z.; Zhang Q.; Journal of Hazardous Materials 137 (2006) 1115-1122.

[3] Gogate P.R.; Ultrasonics Sonochemistry 15 (2008) 1-15.

[4] Wang Y.; Gu B.; Xu W.; Journal of Hazardous Materials 162 (2009) 1159-1164.

[5] Fang Z.; Zhang Y.; Lu Y.; Ma G.; J. Chen, D. Liu, X. Ye, Food Chemistry 113 (2009) 884-888.

[6] Martus P.; Puttmann W.; The Science of the Total Environment 307 (2003) 19-33.

[7] Peričin D.; Krimer V.; Trivić S.; Radulović L.; Food Chemistry 113 (2009) 450-456.

[8] King R.A.; May B.L.; Davies D.A.; Bird A.R.; Analytical Biochemistry 384 (2009) 27-33.

[9] Ofomaja, A.E.; Chemical Engineering Journal, 143 (2008) 8595.

[10] Wu, S.; Yu, L.; Xiao, F.; You, X.; Yang, C.; Cheng, J.; Journal of Alloys and Compounds, 724 (2017) 625-632.

[11] Xiao, Y.; Wan, M.; Jenkins, K.J.; Wu, S.P.; Cui, P.Q.; Journal of Materials in Civil Engineering, 29 (2017) 04017166.

[12] Ahmed, K.; Rehman, F.; Pires, C.T.G.V.; Rahim, A.; Santos, A.L.; Airoldi, C.; Microporous and Mesoporous Materials., 236 (2016) 167-175.

[13] [32] G. Norwitz, J. Farino, P.N. Keliher, Interference of oxidants in the determination of phenol by the 4-aminoantipyrine and ultraviolet ratio spectrophotometric methods, Anal. Chem. 51 (11) (1979).

[14] P.A. Realini, Determination of priority pollutant phenols in water by HPLC, J. Chromatogr. Sci. 19 (3) (1980) 124-129.

[15] J. Farino, G. Norwitz,W.J. Boyko, P.N. Keliher, Study of the behaviour of various phenolic compounds in the 4aminoantipyrine and ultraviolet-ratio spectrophotometric methods without and with distillation, Talanta 28 (9) (1981) 705-708.

[16] A. Shahat, T., Sabine; Sensitive, selective, and rapid method for optical recognition of ultra-traces level of $\mathrm{Hg}(\mathrm{II}), \mathrm{Ag}(\mathrm{I}), \mathrm{Au}(\mathrm{III})$, and $\operatorname{Pd}(\mathrm{II})$ in electronic wastes, Sens. Actuators B 245 (2017) 789 .
[17] American Public Health Association, 1995, Standard methods for the examination of water and wastewater (19th ed.): Washington, D.C., American Public Health Association Inc., p. 536 to $5-39$.

[18] Ogan K.L.; Katz E.D.; Retention characteristics of several bonded-phase liquid chromatography columns for some polycyclic aromatic hydrocarbons, Journal of Chromatography A, 188 (1) (1980) 115-127.

[19] Langmuir I.; The adsorption of gases on plane surfaces of glass, mica and platinum. J. Am. Chem. Soc. 40 (1918) 13611403. 